\title{
RELATO HISTÓRICO Y DISEÑO CONSTITUCIONAL EN SUIZA (1798-1891)
}

\section{HISTORICAL NARRATIVE AND CONSTITUTIONAL DESIGN IN SWITZERLAND (1798-1891)}

\author{
Jordi Jaria-Manzano \\ Universitat Rovira i Virgili
}

\begin{abstract}
SUMARIO: I. INTRODUCCIÓN.- II. EL FRACASO DE LA REPÚBLICA HELVÉTICA.- III. REGENERACIÓN Y ESTADO FEDERAL.- IV. EL 'RÜTLISCHWUR' COMO QUINTAESENCIA DE LA IDENTIDAD CONSTITUCIONAL SUIZA.- V. LA IMPLANTACIÓN DE LA DEMOCRACIA DIRECTA A NIVEL FEDERAL Y SU INCIDENCIA EN LA IDEA DE CONSTITUCIÓN.- VI. CONCLUSIÓN: LA CONSTITUCIÓN COMO ACTUALIZACIÓN DEL RELATO HISTÓRICO (Y LA ESTABILIDAD POLÍTICA).- VII. BIBLIOGRAFÍA.
\end{abstract}

Resumen: La existencia de una iniciativa popular de reforma constitucional favorece que la Constitución suiza sea reformada de modo habitual. Sin embargo, a pesar de haber experimentado innumerables revisiones parciales y dos revisiones totales (en 1874 y en 1999), los elementos constitucionales fundamentales que definen la identidad del sistema político permanecen inalterables desde 1848, dando lugar a uno de los estados más estables de Europa desde el punto de vista constitucional $\mathrm{y}$, desde luego, al régimen republicano más longevo del Viejo Continente. El presente trabajo explora como el relato histórico es fundamental en la construcción de la identidad constitucional del Estado federal suizo, que se realiza a través de una idea de continuidad con el pasado, que proporciona un fundamento extremadamente sólido para la continuidad del sistema. Para ello, se analiza el período comprendido entre la llegada de la Modernidad política a Suiza con la instauración de la República Helvética, en 1798, hasta la incorporación a la Constitución de la iniciativa popular de reforma constitucional en 1891.

Abstract: The existence of the popular initiative favours the Swiss Constitution being amended on a regular basis. However, despite having undergone innumerable partial revisions and two total revisions (in 1874 and in 1999), the fundamental constitutional elements that define the identity of the political system remain unchanged since 1848, giving rise to one of the most stable states in Europe, from the constitutional point of view, and to the longest running republican regime in the Old Continent. The present work explores how the historical narrative is fundamental in the construction of the constitutional identity of the Swiss federal state, carried out through an idea of continuity with the past, which provides an extremely solid 
foundation for the stability of the system. This paper analyses the period between the beginning of political Modernity in Switzerland, with the establishment of the Helvetic Republic in 1798, and the incorporation into the Constitution of the popular initiative for the revision of the Constitution in 1890.

Palabras clave: Suiza; Federalismo; Democracia directa; Cultura constitucional; identidad política.

Key Words: Switzerland; Federalism; Direct Democracy; Constitutional Culture; Political Identity.

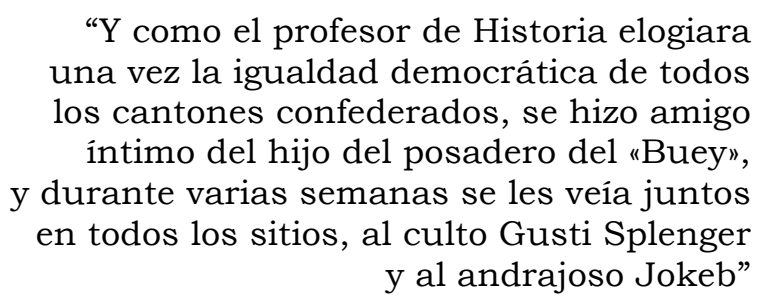

Carl Spitteler, Gustav (1892) ${ }^{1}$

\section{INTRODUCCIÓN}

El artículo 88.3 vigente de la Constitución federal suiza establece que la Confederación está obligada a reemplazar los caminos y senderos para peatones que suprima ${ }^{2}$. Se trata de una disposición introducida después de la votación popular que se llevó a cabo el 23 de septiembre de $2018^{3}$. Se trata de una norma que no parece tener un contenido propio de una constitución formal, sino más bien una disposición adecuada para figurar en la legislación administrativa sectorial. La Constitución federal suiza está repleta de disposiciones similares, hasta el punto de que se ha propuesto la distinción entre Essentialien y

1 La cita está tomada de Carl Spitteler, Imago. Narraciones breves. Gustav, Rueda. Madrid, 2002 (versión castellana no acreditada), p. 201. Carl Spitteler fue el primer suizo galardonado con el premio Nobel de literatura, en 1919.

2 Las citas de la Constitució federal suiza las haré a partir de la versión oficial en francés disponible en <https://www.admin.ch/opc/fr/classifiedcompilation/19995395/index.html>. Si el lector lo prefiere, puede consultar la versión oficial en alemán (<https://www.admin.ch/opc/it/classifiedcompilation/19995395/index.html>) o en italiano (<https://www.admin.ch/opc/de/classified-compilation/19995395/index.html>).

Existe asimismo una versión no oficial en romanche (<https://www.admin.ch/opc/rm/classified-compilation/19995395/index.html>) y otra en inglés (<https://www.admin.ch/opc/en/classifiedcompilation/19995395/index.html>), proporcionadas en ambos casos por el Consejo Federal.

3 Vid., de nuevo, <https://www.admin.ch/opc/fr/classifiedcompilation/19995395/index.html>. 
Akzidentalien en relación con los contenidos constitucionales ${ }^{4}$. Efectivamente, como nota Bernard Chantebout, la Constitución federal suiza presenta, de manera particularmente frecuente, disposiciones formalmente constitucionales que, por su contenido material, deberían figurar en una ley ordinaria ${ }^{5}$.

Ello se debe a la existencia de la iniciativa popular de reforma de la Constitución federal, a la que me voy a referir con mayor detalle más adelante, y a la inexistencia de una iniciativa popular equivalente en relación con las leyes ordinarias, lo que traslada buena parte de las discusiones politicas canalizadas a través de la democracia directa al terreno de la reforma de la Constitución. Sin embargo, desde el punto de vista del estudio que aquí se presenta, lo relevante no es la mecánica de funcionamiento de las instituciones de democracia directa y su incidencia en los contenidos de la Constitución, sino el hecho de que la Carta Magna está sometida a un proceso de reforma continua sin que ello afecte en nada a la estabilidad del sistema político, que se mantiene sin cambios de calado desde la instauración del Estado federal en 1848, lo que hace de Suiza uno de los sistemas politicos europeos de mayor continuidad institucional y, desde luego, el más longevo entre las repúblicas del Continente ${ }^{6}$.

A mi juicio, ello se debe al relieve que adquiere el relato histórico en la legitimación de las instituciones, de una importancia notablemente superior a las disposiciones concretas incorporadas la Constitución federal, de modo que no se produce una sacralización de sus contenidos concretos $^{7}$. De hecho, la importancia del relato histórico en la configuración del sistema político afecta a la propia idea de constitución, que no se concibe como un contrato social originario que da nacimiento a la comunidad politica y tampoco como un texto sagrado en el que se hallan depositados los elementos esenciales que definen su identidad ${ }^{8}$. Más bien la Constitución federal es un proceso de elaboración continua de una identidad histórica que la trasciende y

4 Vid. Thomas Dunn, Die richtige Verfassung, Schulthess. Zúrich, 1971, p. 13.

5 Vid. Bernard Chantebout, Droit constitutionnel et science politique, Economica. Paris, 1978, p. 48.

6 Sin embargo, la bibliografía sobre el sistema constitucional suizo y su evolución histórica es más bien escasa en castellano. Existe la descripción clásica que ofrece Manuel García-Pelayo, Derecho constitucional comparado, Alianza, Madrid, 1984, p. 521ss. Además, vid. Remedios Sánchez Ferriz, "El sistema político suizo", en Juan Ferrando Badía (ed.), Regimenes politicos actuales, Tecnos. Madrid, 1995 (3 ${ }^{a}$ edición), pp. 497-534; y Jordi Jaria i Manzano, "El federalismo suizo. Una respuesta a una sociedad plural", Revista Vasca de Administración Pública / Herri-Arduralaritzako Euskal Aldizkaria, nº. 61(I), 2001, pp. 89-136.

7 Sobre la importancia del relato histórico en la legitimación de la estructura politica en Suiza, vid., por todos, Norbert Domeisen, Schweizer Verfassungsgeschichte, Geschichtphilosophie und Ideologie, Lang, Berna, 1978, p. 21ss.

8 En relación con la idea de la constitución como libro sagrado, en la tradición tanto norteamericana como europea, vid. Vid. Peter Häberle, Europäische Verfassungslehre, Nomos. Baden-Baden, 2011 (6ª . edición), p. 9 y 205. 
que se va actualizando en el devenir de su texto, sin que éste adquiera, por su parte' una dimensión transcendente.

En definitiva, la idea fundamental en el constitucionalismo suizo es que la comunidad politica se organiza de acuerdo con unos principios ancestrales -que se concretan en las instituciones de democracia directa y la organización federal ${ }^{9}$ - que se actualizan con la llegada de la Modernidad política, de modo que tanto los procesos políticos en los cantones más progresistas a lo largo de la década de los treinta del siglo XIX como, finalmente, la eclosión de la Constitución federal en 1848 no constituyen una ruptura con el pasado, sino más bien una recuperación de la identidad prístina originaria, perdida a lo largo de una evolución histórica en la que se habría ido produciendo una decadencia de las instituciones tradicionales ${ }^{10}$.

La presentación de los nuevos desarrollos democráticos y liberales como una puesta al día de los orígenes políticos de la Confederación será determinante para permitir su legitimación ante la comunidad política, así como para relativizar el contenido de la Constitución normativa. En las páginas siguientes presento el proceso histórico comprendido ente el fracaso de la República Helvética, la primera forma estatal panhelvética, y la introducción en la Constitución federal de la iniciativa popular de reforma constitucional, tratando de hacer explícita la construcción historicista que sostiene las ideas fundamentales del sistema político y las proyecta hacia el futuro. Para ello, me refiero, en primer lugar, a la República Helvética; seguidamente, a la llamada Regeneración que culmina en la Constitución federal de 1848; después, a la vinculación entre el texto constitucional y el Rütlischwur, el origen último de la Confederación, en 1291; para encarar, finalmente, la introducción de las instituciones de democracia directa que caracterizan al sistema constitucional suizo hasta la actualidad, en el corto período comprendido entre 1874 y 1891.

9 El federalismo y la democracia suelen citarse en la literatura como los pilares fundamentales sobre los que se sustenta el sistema politico suizo. Vid., por todos, Andreas Auer, Giorgio Malinverni, Michel Hottelier, Droit constitutionnel Suisse. I. L'Etat, Stämpfli. Berna, 2000, p. 293.

10 Es importante, en todo caso, tomar en consideración que, dada su diversidad, la comunidad politica no construye sobre una base étnica, sino politica. Vid., en este sentido, Thomas Fleiner, "Die Stellung der Minderheiten im schweizerischen Staatsrecht", en Ulrich Häfelin, Walter Haller, Dietrich Schlindler (editors), Menschenrechte, Föderalismus, Demokratie. Festschrift zum 70. Geburtstag von Werner Hägi, Schulthess. Zúrich, 1979, p. 120. Sin embargo, contrariamente a lo que sucede en el caso de otras naciones politicas paradigmáticas, como es el caso de Estados Unidos o Francia, la identidad política no se construye sobre un decisión fundacional revolucionaria, sino sobre la continuidad histórica de unos principios fundamentales que definen la identidad de la comunidad politica. 


\section{EL FRACASO DE LA REPÚBLICA HELVÉTICA}

Antes de la invasión francesa y la instauración de la República Helvética, la Confederación consistía en una compleja alianza de distintos pequeños estados situados entre la cara norte de los Alpes y la cara sur del Jura, y entre los lagos Leman y Constanza, que sostenian una unión defensiva ante las amenazas exteriores ${ }^{11}$. Estos estados serán posteriormente los cantones ${ }^{12}$. Sus diferencias eran remarcables, desde el punto de vista politico, y podian distinguirse, fundamentalmente, tres tipos, a saber: cantones rurales de Landsgemeinde - gobernados por una asamblea a la que pertenecían todos los hombres del estado, como sería el caso de Uri-13, cantones urbanos de constitución corporativa - cuyo gobierno era ejercido por los gremios o Zünfte, con el caso paradigmático de Zúrich- y los cantones urbanos de constitución aristocrática - gobernados por una asamblea de la que formaban parte solo las familias nobles, como sería el caso de Friburgo o Berna-14.

En el contexto de los conflictos entre los diferentes estados que formaban parte de la Confederación a causa de la Reforma, el Vorort, esto es, el cantón de Zürich, fracasó en su intento de imponerse como

11 En palabras de William Rappard, se trataba, en definitiva, de lo siguiente: "S'unir ou périr, telle était l'alternative que l'expérience même de la vie commune posait à la clairvoyance des magistrats et au civisme du peuple". Vid. William E. Rappard, "Considérations historiques sur la Constitution fédérale de 1848" [1948], en Varia Politica, Poligraphiques. Zúrich, 1953, p. 222.

12 El término 'cantón' del latín 'quantonus' a través del francés 'canton' ha sido utilizado por la diplomacia francesa, primero, y después por otras potencias para referirse a los estados miembros de la Confederación Helvética. En el Derecho constitucional suizo fue introducido, al parecer, en el proyecto constitucional de Peter Ochs desde el que saltó al texto de la primera Constitución de la República Helvética (1798). En la antigua Confederación -que, por otra parte, era, casi de manera exclusiva, de lengua alemana, ya que los actuales territorios francófonos, aparte de Friburgo, o no figuraban dentro de la Confederación, como en el caso de Ginebra, o eran territorios vasallos, como en el caso de Vaud respecto a Berna-, se usaba primitivamente la expresión alemana Ort y, más tarde, la palabra Stand. Aún hoy, en alemán, la segunda cámara de la Asamblea Federal, donde están representados los cantones, se llama Ständerat. Vid. en relación con ello, Andreas Auer, Giorgio Malinverni, Michel Hottelier, Droit constitutionnel Suisse. I. L'Etat, op. cit., p. 312; y Alfred Kölz, Histoire constitutionnelle de la Suisse moderne. Ses fondements idéologiques et son évolution institutionnelle dans le contexte européen, de la fin de l'Ancien Régime à 1848, Stämpfli, Bruylant. Berna, Bruselas, 2006, p. 116-117.

13 En la actualidad solamente subsisten dos cantones que mantienen la Landsgemeinde, a saber, Glarus (art. 61 de la Constitución cantonal, de 1 de mayo de 1988), y Appenzell-Innerrhoden (art. 16.1 de la Constitución cantonal, de 24 del diciembre de 1872). En ambos casos, los miembros de la Landsgemeinde se definen en los mismos términos que el cuerpo electoral en los demás cantones, a saber, los suizos y suizas residentes en el cantón y mayores de dieciocho años (art. 56 de la Constitución cantonal de Glarus, y art. 16.1 de la constitución cantonal de AppenzellInnerrhoden).

14 Vid. Alfred Kölz, Histoire constitutionnelle de la Suisse moderne. Ses fondements idéologiques et son évolution institutionnelle dans le contexte européen, de la fin de l’Ancien Régime à 1848, op. cit., pp. 116-117. 
centro político, de modo que la diversidad continuó existiendo en los siglos siguientes y se conservó el estatuto particular de los estados alpinos rurales, esto es, los cantones originarios, que habian logrado imponer la inmediatez imperial en las luchas contra los Habsburgo y que conservaban su tradicional organización asamblearia a través de las respectivas Landsgemeinden. Sin embargo, ello no obsta al predominio de los estados dominados por la aristocracia urbana desde luego, en absoluto democráticos- en la Edad Moderna y, particularmente, a finales del siglo XVIII, cuando se inicia el proceso de modernización política de la Confederación con la invasión francesa y la implantación de la República Helvética ${ }^{15}$.

El ejemplo más claro del predominio de los cantones no asamblearios -fueran dominados por un patriciado noble, como el caso de Berna, o por una oligarquía comercial, como el caso de Zúrich- es el hecho de que este último estado hubiera devenido "canton directeur permanent" en la Antigua Confederación a lo largo de la Edad Moderna, de modo que el burgomaestre de Zúrich ostentaba la presidencia de la Dieta Confederal ${ }^{16}$. Así, aunque Zúrich no había tenido la capacidad de impulsar la creación de un estado unitario en el espacio ocupado por la Confederación Helvética a causa de su derrota en las guerras religiosas del siglo XVI, había logrado el reconocimiento de una primacía, que era también la de la hegemonía de las instituciones estamentales en relación con la democracia rural, la cual va a mitificarse en el tránsito hacia la Modernidad politica.

Este tránsito se abre con la implantación de la República Helvética en 1798, después de la derrota de la resistencia local -básicamente bernesa- ante la invasión de los ejércitos napoleónicos ${ }^{17}$. Previamente a este hecho, no hay propiamente un estado suizo. La antigua Confederación (alte Eidgenossenschaft) era propiamente un conjunto de estados, vinculados a través de "[p]actes, chartes et convenants", aparte de "multiples pratiques et usages, qui le plus souvent reposaient sur un

15 Vid. Alfred Kölz, Histoire constitutionnelle de la Suisse moderne. Ses fondements idéologiques et son évolution institutionnelle dans le contexte européen, de la fin de l'Ancien Régime à 1848, op. cit., p. 10.

16 Ibid.

17 Sobre la República Helvética, en general, vid. Alfred Kölz, Histoire constitutionnelle de la Suisse moderne. Ses fondements idéologiques et son évolution institutionnelle dans le contexte européen, de la fin de l'Ancien Régime à 1848, op. cit., p. 108ss.; así como Jean-François Aubert, Traité de droit constitutionnel suisse, Ides et Calendes. Neuchâtel, 1967, pp. 5 y 6. Asimismo, en relación con la Helvética, así como la época posterior, bajo el Acta de Mediación, otorgada por Napoleón en 1803, vid. el estudio clásico y monumental de Eduard His, Geschichte des neuen Schweizerischen Staatsrechts I. Die Zeit der Helvetik und der Vermittlungsakte. 1798 bis 1813, Helbing \& Lichtenhahn. Basilea, 1920; así como también, mucho más brevemente, William E. Rappard, Die Bundesverfassung, Polygraphischer. Zúrich, 1948 (versión alemana, a partir del original francés, a cargo de A. Lätt), p. 21ss. Aunque, en castellano, la bibliografia sobre el constitucionalismo suizo es más bien escasa, en relación la República Helvética y el Acta de Mediación, puede consultarse Manuel García-Pelayo, Derecho constitucional comparado, op. cit., p. 527ss. 
accord tacite des membres de la Confédération"18. En cualquier caso, a pesar de tener una existencia común que se remontaba a la Edad Media, "la Confédération des treize cantons n'était pas basée sur un pacte unique incluant l'ensemble des cantons"19.

La República Helvética es, en consecuencia, el primer estado suizo y responde a las ideas de la Revolución francesa. Ciertamente, antes de la implantación de la Helvética se había ido desarrollando una conciencia sobre la necesidad de renovación política de las antiguas instituciones de la Confederación, que debían parecer a los contemporáneos más avanzados algo parecido a lo que las del Imperio le parecian a Pufendorf ${ }^{20}$. Efectivamente, el marco politico de la antigua Confederación aparece como algo manifiestamente envejecido en tiempos de la Revolución francesa y, aparentemente, maduro para un cambio en la línea de los nuevos postulados provenientes del otro lado del Jura ${ }^{21}$. Así, pues, cuando las tropas francesas invaden el territorio confederado en 1798 a raíz de un levantamiento revolucionario en Vaud, entonces un territorio vasallo del estado de Berna, inauguran un periodo histórico de profundas transformaciones constitucionales que culminará en la Constitución federal de $1848^{22}$. Será en este período en que se implantarán las ideas politicas de la Ilustración transformando la antigua Confederación en un estado federal moderno ${ }^{23}$.

18 Vid. Alfred Kölz, Histoire constitutionnelle de la Suisse moderne. Ses fondements idéologiques et son évolution institutionnelle dans le contexte européen, de la fin de l'Ancien Régime à 1848, op. cit., p. 9.

19 Ibid.

20 Recuérdese la expresión de Samuel Pufendorf al referirse al Sacro Imperio de la Nación Alemana: “irregulare aliquod et (tantum non) monstro simile". La expresión aparece en un opúsculo publicado en el 1667, firmado con el pseudónimo de Severino de Monzambano. Sobre ello, vid. Marcus Llanque, Politische Ideengeschichte - Ein Gewebe politischer Diskurse, Oldenbourg. Múnich, 2008, p. 206; y Dieter Wyduckel, "La soberanía en la historia de la dogmática alemana", Fundamentos. Cuadernos monográficos de Teoría del Estado, Derecho Público e Historia Constitucional 1, 1998, disponible

<http: / / 156.35.33.98/constitucional/fundamentos/primero/pdf/wyducke.pdf>

en [última visita el 22 de octubre de 2020].

21 Vid. Norbert Domeisen, Schweizer Verfassungsgeschichte, Geschichtphilosophie und Ideologie, op. cit., p. 24.

22 Vid. Roland Ruffieux, "Les données de 1'histoire constitutionnelle", Alois Riklin (ed.), Handbuch Politisches System der Schweiz. 1. Grundlagen / Manuel Système politique de la Suisse. 1. Le contexte, Paul Haupt. Berna, Stuttgart, 1983, p. 122.

23 Vid. en este sentido, Felix Renner, Der Verfassungsbegriff im staatsrechtichen Denken der Schweiz im 19. und 20. Jahrhundert, Schultess, Zúrich, 1968, p. 113, que cita, en relación con ello a Eduard His, probablemente el historiador constitucional suizo más relevante, autor de tres volúmenes de referencia en relación con la materia que se inician precisamente con la implantación de la República Helvética, que se publicaron entre 1920 y 1938, cuyo primer volumen cito más arriba en relación precisamente con la Helvética y el tercero, más abajo, en relación con la implantación del Estado federal. 
La República Helvética, si bien implantada a través de poder extranjero, parece que se corresponde con las ansias de cambio político de, al menos, una parte significativa de la población. En todo caso, supone hacer tabla rasa con el pasado y, en particular, la supresión de la rica complejidad politica de la antigua Confederación a través de la implantación de un estado unitario, debido al vínculo que se establecía, desde una perspectiva jacobina, entre federalismo y privilegios ${ }^{24}$. E1 cambio, en consecuencia, es traumático y, ciertamente, ya nunca más nada va a ser lo mismo ${ }^{25}$. Sin embargo, la estructura unitaria casa mal con la diversidad lingüística, religiosa y social de los territorios de la antigua Confederación, que, además, carecen de un centro claro que pueda ejercer una fuerza centripeta que coadyuve a la su consolidación, de modo que se opera una ruptura con el pasado que tiene algo brutal y de caprichoso ${ }^{26}$.

Efectivamente, la Helvética supone un desajuste entre las instituciones politicas de nueva planta y el sustrato social sobre el que se implantan, lo que, finalmente, va a provocar su fracaso; aunque va a dejar una huella duradera con la incorporación de las ideas de la Revolución francesa a la tradición politica local, que va a ser reelaborada, como vamos a ver seguidamente, para reajustarse a esas nuevas concepciones ${ }^{27}$. Sea como sea, la implantación de una estructura politica que ignoraba la complejidad y sofisticación de la antigua Confederación no va a consolidarse, dejando un recuerdo ambivalente en la historiografia posterior, en que se toma en

24 Vid. Roland Ruffieux, "Les données de l'histoire constitutionnelle", op. cit., p. 124.

25 Vid. Alois Riklin y Silvano Möckli, "Werden und Wandel der schweizerischen Staatsidee", en Alois Riklin (ed.), Handbuch Politisches System der Schweiz. 1. Grundlagen / Manuel Système politique de la Suisse. 1. Le contexte, op. cit., p. 22.

26 Vid. Jean-François Aubert, Traité de droit constitutionnel suisse, op. cit., p. 5. En este sentido, diferentes contemporáneos ponen de manifiesto su incomodidad con la centralización geométrica de cuño francés que incorpora la Helvética, como, por ejemplo, el Bürgermeister de Basilea, Johann Karl Wieland. Vid., en este sentido, James H. Hutson, The Sister Republics. Switzerland and the United States from 1776 to the Present, Library of the Congress. Washington, 1991, p. 33.

27 Vid. Jean-François Aubert, Traité de droit constitutionnel suisse, op. cit., p. 9. Por otra parte, de hecho, la propia pluralidad cultural que, actualmente, asociamos con Suiza, particularmente, desde el punto de vista lingüístico es, hasta cierto punto, una consecuencia de la implantación de la República Helvética, que va a suponer la liberación de los territorios vasallos de lengua romance y, con ello, la incorporación del francés y del italiano a una cultura que, hasta entonces, había sido predominantemente germánica - aunque el uso del francés como lengua de cultura ya se había implantado en algunos lugares, particularmente, en los cantones aristocráticos en que las familias nobles mantenían relaciones con la Monarquía francesa, sobre todo, a través de la prestación de servicios armados, como sería el caso de Friburgo, donde, aunque se trata de un cantón bilingüe, el francés es la lengua predominante, o Berna, que ejercía el dominio feudal sobre Vaud, y que también hoy es un cantón bilingüe- - Por otra parte, la República Helvética, cuyo diseño institucional se inspiraba en la Constitución francesa del año III (1795), incorporó un gobierno colegial, según el modelo del directorio francés, que se ha consolidado como estructura del poder ejecutivo hasta el día de hoy. 
consideración tanto su contribución a la modernización política de Suiza como su desconocimiento de las sensibilidades locales de acuerdo con su orientación jacobina, hasta el punto de que se la ha calificado como un "souvenir maudit"28.

Efectivamente, en 1803, llevado tanto por consideraciones estratégicas de alcance europeo como por la inestabilidad politica local y la fragilidad del marco institucional importado de Francia, Napoleón Bonaparte, Primer Cónsul de la República Francesa, reconsidera el régimen constitucional suizo y otorga, como máxima autoridad de la potencia ocupante, la llamada Acta de Mediación, por la que se restaura la organización confederal, si bien sin romper con los principios de la Revolución francesa previamente importados con la invasión de cinco años atrás ${ }^{29}$. Con ello, se dejaba atrás la estructura unitaria impuesta por la República Helvética, que no volveria a reivindicarse jamás ${ }^{30}$.

Se consolida la idea de que la modernización politica que pueda operarse, de acuerdo con los nuevos principios revolucionarios, en el territorio de la Antigua Confederación se hará sobre el presupuesto de la pluralidad politica tradicional, de acuerdo con la función defensiva que ésta ha jugado en relación con los pequeños estados que forman parte de ella desde su fundación en el siglo XIII. En definitiva, con el final de la Helvética, se va imponiendo la convicción de que la superación del ancien régime solo es posible sobre el respeto a las tradiciones politicas locales.

\section{REGENERACIÓN Y ESTADO FEDERAL}

La derrota de Napoleón va a dar lugar a la restauración de las instituciones tradicionales en 1815, dejando atrás del sistema derivado del Acta de Mediación, abriendo un nuevo periodo histórico ${ }^{31}$. Aunque no se van a recuperar los antiguos vasallajes feudales, sí que va a reprenderse el dominio de las oligarquías ciudadanas en los cantones aristocráticos, de acuerdo con el clima de restauración del ancien régime promovido por el Congreso de Viena ${ }^{32}$. Se inicia, entonces, un período de estabilidad favorecido por los nuevos equilibrios de poder continentales y por el control que ejercen las grandes potencias sobre los eventuales episodios liberales que puedan producirse, como

28 Vid. William E. Rappard, "Considérations historiques sur la Constitution fédérale de 1848" op. cit., p. 218.

29 Vid. Jean-François Aubert, Traité de droit constitutionnel suisse, op. cit., p. 6ss.

30 Vid. Roland Ruffieux, "Les données de 1'histoire constitutionnelle”, op. cit., p. 124.

31 Vid. Fritz Fleiner, "Die Gründung des Schweizerischen Bundesstaates im Jahre 1848" [1898], en Ausgewählte Schriften und Reden, Polygraphischer. Zurich, 1941, pp. 53-80, para una evolución de la Confederación desde los tiempos de la Restauración hasta la Constitución federal de 1848.

32 Sobre el Pacto Federal de 1815, por el que se restaura, hasta cierto punto, la antigua Confederación, vid. Rappard, Die Bundesverfassung, op. it., p. 31ss. 
muestra, sin ir más lejos, la invasión de los Cien Mil Hijos de San Luis en el caso español en $1823^{33}$.

Sin embargo, durante la década de los treinta y, una vez más, favorecido por los acontecimientos que suceden en Francia, el liberalismo se recupera y va imponiéndose en los cantones protestantes, donde también se ha ido produciendo una cierta modernización socioeconómica ${ }^{34}$. Efectivamente, la Revolución orleanista de 1830 marca tradicionalmente el paso del período de la Restauración al período llamado de la Regeneración, en el que se produce una progresiva liberalización política en los cantones urbanos más desarrollados desde el punto de vista de la implantación de una economía capitalista moderna ${ }^{35}$.

La caída de Carlos XVIII es, en definitiva, el disparo de salida de una nueva época política, de modo que los acontecimientos franceses vuelven a marcar la hora politica europea - precisamente de 1830 es la Constitución belga-, lo que, en el caso de Suiza iniciar un período de cambio político, en primer lugar, a nivel cantonal que acabará culminando dieciocho años más tarde con la Constitución federal ${ }^{36}$. En principio, la Regeneración supone, de hecho, la progresiva implantación de instituciones politicas modernas, de acuerdo con la herencia revolucionaria ${ }^{37}$. Sin embargo, se utiliza la identidad histórica, hábilmente reconstruida, para justificar los cambios politicos, que se presentan como una recuperación de un pasado mítico, más libre, por contraposición al carácter fundacional $-\mathrm{y}$, en consecuencia, orientado al futuro- que tienen los procesos revolucionarios en Estados Unidos y en Francia.

Efectivamente, este proceso de modernización política se conoce en la historiografia suiza como la Regeneración, un renacimiento político e intelectual vinculado al auge del liberalismo, que, sin embargo, remite, efectivamente, a "certaines libertés démocratiques antérieures au renforcement de l'aristocratie des XVIIe et XVIII siècles, des libertés que l'on évoque alors confusément et que l'on fait remonter à un passé lointain et obscur"38. Un buen ejemplo de ello es el caso de Ginebra, donde James Fazy y sus partidarios radicales en el Grand Conseil introducen una serie de reformas en el régimen político de la ciudad-estado,

33 Vid. Roland Ruffieux, "Les données de l'histoire constitutionnelle", op. cit., p. 123.

34 Vid. Alois Riklin, Silvano Möckli, "Werden und Wandel der schweizerischen Staatsidee", op. cit., p. 29.

35 Vid. Jean-François Aubert, Traité de droit constitutionnel suisse, op. cit., p. 18.

36 Vid. William E. Rappard, "Considérations historiques sur la Constitution fédérale de 1848” op. cit., p. 220. Para una valoración del período de la Regeneración, vid. Jean-François Aubert, Traité de droit constitutionnel suisse, op. cit., p. 20ss.

37 Vid. Roland Ruffieux, "Les données de l'histoire constitutionnelle", op. cit., p. 124.

38 Vid. Alfred Kölz, Histoire constitutionnelle de la Suisse moderne. Ses fondements idéologiques et son évolution institutionnelle dans le contexte européen, de la fin de l’Ancien Régime à 1848, op. cit., p. 227. 
omitiendo hábilmente la mención de las fuentes utilizadas fundamentalmente francesas y norteamericanas; pero también ginebrinas, aunque del periodo revolucionario-. Parece evidente, en la opinión de Alfred Kötz, la influencia de las constituciones de la Francia revolucionaria en la Regeneración, particularmente en los casos de Ginebra, Berna y Vaud $^{39}$. Sin embargo, lo que Fazy y los suyos presentan ante la ciudadania de Ginebra es una reforma que enlaza con "des institutions de l'ancienne République genevoise"40.

Esta actitud, como veremos seguidamente, va a reproducirse como estrategia de legitimación del Estado federal fundado en 1848 y supone la imposición de las ideas predominantes en los cantones liberales y protestantes sobre las que dominan en los cantones católicos y conservadores $^{41}$. Después de que la Regeneración se imponga en diversos estados de la Confederación, enlazando las nuevas ideas políticas con el recuerdo mítico de las antiguas instituciones confederadas, se a producir el choque definitivo entre los cantones conservadores y los liberales en el marco de la Guerra del Sonderbund $^{42}$. La victoria de los segundos va a dar lugar a la Constitución de 1848 y la fundación del Estado federal ${ }^{43}$.

En este escenario, va a desarrollarse un ejercicio de legitimación del nuevo orden que enlaza con lo que ya se habia ensayado, a lo largo de la Regeneración en los cantones liberales, esto es, la vinculación entre las antiguas instituciones confederadas y el nuevo régimen político, destacando, particularmente, la importancia de la democracia ancestral de las Landsgemeinde, lo que va a incidir, de modo remarcable, no solo en la consolidación de la legitimación del Estado federal, sino en su evolución política posterior ${ }^{44}$. Un ejemplo notorio de ello es Ignaz Paul Vital Troxler, influyente personaje de la Regeneración $\mathrm{y}$ actor remarcable en la producción de las ideas que articularon la

39 Vid. Alfred Kölz, Histoire constitutionnelle de la Suisse moderne. Ses fondements idéologiques et son évolution institutionnelle dans le contexte européen, de la fin de l'Ancien Régime à 1848, op. cit., p. 682.

40 Ibid.

41 Ello va a producirse a pesar de las evidentes diferencias entre el altes Eidgenossenchaft y el nuevo Bundesstaat, empezando por la propia existencia estatal del segundo, formalizada en la nueva Constitución, como señala Jean-François Aubert, Traité de droit constitutionnel suisse, op. cit., p. 197.

42 Sobre la Guerra del Sonderbund, vid. op. cit., p. 29ss.

43 Para la elaboración de la Constitución de 1848, vid. Alfred Kölz, Histoire constitutionnelle de la Suisse moderne. Ses fondements idéologiques et son évolution institutionnelle dans le contexte européen, de la fin de l'Ancien Régime à 1848, op. cit., p. 597ss.

44 En general, sobre la Constitución de 1848 y el período que se abre con ella en la historia político-constitucional suiza, vuelve a ser de interés la obra monumental de Eduard His, en este caso su tercer tomo (Geschichte des neuen Schweizerischen Staatsrechts III. Der Bundesstaat von 1848 bis 1914, Helbing \& Lichtenhahn. Basilea, 1938). 
Constitución de 1848. Troxler señala que el Estado federal resultante enlaza con los "ältesten und ächtesten eidgenössischen Bünde"45.

Según Troxler, la evolución política de la Confederación desde el siglo XV habría destruido los Volksbünde originarios, consolidando las oligarquías y el dominio de las ciudades. El liberalismo, en este contexto, aparece, pues, como una recuperación de la libertad originaria, aunque, por supuesto, el artificio no escapa a los conservadores, como, por ejemplo, Philipp Anton von Segesser ${ }^{46}$. En consecuencia, el Estado federal de 1848 seria, para Troxler, una reconstrucción de los fundamentos primitivos del altes Eidgenossenschaft47. Es remarcable aquí tanto el vínculo que se establece entre la Modernidad politica y las antiguas instituciones, como que el modelo que se toma es la Confederación originaria, organización federal de los cantones rurales de Landsgemeinde. Por el contrario, la organización aristocrática de los cantones urbanos se presenta como la manifestación del ancien régime que debe superarse ${ }^{48}$.

Todo ello, en definitiva, conecta con el Rütlischwur como hecho político primigenio, lo que, a su vez, se vincula al papel que las luchas de los Orte originarios contra el poder feudal han jugado en la articulación política del Romanticismo alemán ${ }^{49}$. En este sentido, debe recordarse tanto la trama como el impacto del Wilhelm Tell de Friedrich von Schiller, que va a vincular la lucha por la libertad contra la tiranía a los orígenes de la Confederación Helvética ${ }^{50}$. Por otra parte, la concepción de la libertad derivada del mito del Rütlischwur (la uralte schweizerische Volksfreiheit) remite a una idea comunitaria que enlaza con la concepción democrática que se acabará imponiendo en el sistema constitucional suizo por contraposición a la versión estrictamente liberal de la Modernidad politica51.

45 Vid. Felix Renner, Der Verfassungsbegriff im staatsrechtichen Denken der Schweiz im 19. und 20. Jahrhundert, op. cit., p. 187.

46 Vid. op. cit., p. 237.

47 Vid. op. cit., p. 188.

48 Sobre el Antiguo Régimen y, en particular, sobre los regimenes aristocráticos de algunos cantones miembros de la Confederación, vid. Marcel Bridel, Précis de droit constitutionnel et public suisse I, Payot. Lausana, 1965, p. 17 y ss.

49 En este sentido, la historiografia tradicional, que ha configurado el relato hegemónico en la construcción nacional subsiguiente a la constitución del Estado federal, ve el pacto originario de finales del siglo XIII como el nacimiento efectivo de la nación, que se proyecta hacia adelante históricamente a través de la altes Eidgenossenschaft, embrión del actual sistema político. Sobre esto, vid. Norbert Domeisen, Schweizer Verfassungsgeschichte, Geschichtphilosophie und Ideologie, op. cit., p. 27ss.

50 Vid. Friedrich von Schiller, Guillermo Tell, Planeta, Barcelona, 1982 (edición castellana de Justo Molina, con introducción de Alfonsina Janés Nadal).

51 En definitiva, la uralte schweizerische Volksfreiheit no es "die Freiheit des Individuums, sondern die Freiheit des Kollektivs", como señalan Alois Riklin y Silvano Möckli, en "Werden und Wandel der schweizerischen Staatsidee", op. cit., p. 21. En el mismo sentido, se pronunciaría un autor clásico del derecho público suizo, Zaccaria 
Por otra parte, la remisión al Rütlischwur no solo sirve para consolidar la democracia -y, ciertamente, una idea particular de democracia, la democracia directa inspirada en las antiguas Landsgemeinde de los Waldstätten-, sino que también inspira el segundo elemento fundamental del constitucionalismo suizo, a saber, el federalismo, que la República Helvética había obviado, con su consiguiente fracaso. Efectivamente, el pacto fundacional une a los tres cantones originarios para defenderse contra el agresor exterior, de modo que la unión se explica como estrategia para perdurar en el tiempo, no para disolverse en una unidad politica superior ${ }^{52}$. Esta narrativa historicista se desarrollará como estrategia de legitimación del Estado federal implantado en 1848, al mismo tiempo que ejercerá una notable influencia en su evolución política, aunque, de hecho, desde el mismo proceso constituyente existen elementos de ruptura flagrante con el pasado ${ }^{53}$.

En este sentido, va a ser notable la contribución de la Escuela Histórica del Derecho a la hora de enlazar las instituciones de la antigua Confederación con las nuevas estructuras del Estado federal de $1848^{54}$. La idea de continuidad se ha mantenido con notable

Giacometti, tal como señala Felix Renner, en Der Verfassungsbegriff im staatsrechtichen Denken der Schweiz im 19. und 20. Jahrhundert, op. cit., p. 423.

52 La protección de los pequeños estados que forman parte de la Confederación ante los poderosos enemigos exteriores es un elemento fundamental en la identidad política suiza, que da lugar a la organización federal, como señalan Alois Riklin y Silvano Möckli, en "Werden und Wandel der schweizerischen Staatsidee", op. cit., p. 21ss. En particular, esta idea defensiva dará lugar, en el transcurso de la historia, a la proverbial neutralidad suiza.

53 Así, por ejemplo, los miembros de la comisión que elaboró el proyecto de Constitución fueron nombrados para actuar como expertos federales y no como delegados cantonales, rompiendo con las tradiciones asociadas a la Dieta confederal. Vid., en relación con ello, William E. Rappard, "Considérations historiques sur la Constitution fédérale de 1848" op. cit., p. 224. Por otra parte, los cantones del antiguo Sonderbund, además de Appenzell-Innerrohden y del Ticino, cantones asimismo católicos, fueron sometidos a la nueva Constitución a pesar de que la mayoría de su población no la había aceptado. Vid. op. cit., p. 226. Subsiguientemente, debe tenerse en cuenta que la propia aprobación de una constitución federal y la fundación consiguiente de un estado suponian una innovación evidente en relación con el pasado confederado. Ello dio lugar a una notable influencia norteamericana en el diseño institucional del nuevo estado, que, obviamente, suponía asimismo un elemento notorio de ruptura. Vid., en este sentido, James H. Hutson, The Sister Republics. Switzerland and the United States from 1776 to the Present, op. cit., p. 39. En general, sobre la influencia norteamericana en la configuración del Estado federal en Suiza, vid. asimismo. Thomas Fleiner, "E1 federalismo suizo: la influencia del federalismo americano", en VVAA, El federalismo en Europa, Hacer. Barcelona, 1993, pp. 9-43 (versión castellana, a partir del original francés, a cargo de Josep Maria Solé Alseda). En general, para una crítica comprehensiva de la idea de continuidad entre la antigua Confederación y el actual Estado federal, vid. Norbert Domeisen, Schweizer Verfassungsgeschichte, Geschichtphilosophie und Ideologie, op. cit., p. 27ss.

54 Vid. Felix Renner, Der Verfassungsbegriff im staatsrechtichen Denken der Schweiz im 19. und 20. Jahrhundert, op. cit., p. 168. Sobre la idea de continuidad entre el altes Eidgenossenschaft y el nuevo Bundestaat - a través de la República Helvética- se pronunciaron varios autores clásicos del Derecho público suizo, como Carl Hilty (vid. 
persistencia a través de la evolución histórica del Estado federal, de modo que, ya en siglo XX, Leonhard Neidhart defendía que el proceso de creación del Estado federal —que, según su punto de vista, se alarga desde 1832 a 1848 , esto es, vendría a cubrir casi en su totalidad el periodo de la Regeneración- no fue, propiamente, un proceso fundacional, sino que constituyó, sencillamente, una Totalrevision utilizando el término técnico que se halla en el texto constitucional- de los vínculos entre los antiguos estados federados. Con ello, para Neidhart, la aprobación de la Constitución en 1848 y la revisión total de 1874 serían fenómenos equiparables ${ }^{55}$.

En consecuencia, se articula un discurso constitucional idiosincrático, que disimula el impacto de las ideas y las instituciones de la Revolución a través de una afirmación de la pervivencia de la antigua Confederación, meramente renovada en el curso de la construcción del Estado federal, subrayando así del carácter nacional ante las influencias extranjeras, de acuerdo con los postulados propios de la Escuela Histórica del Derecho ${ }^{56}$. En cualquier caso, a partir de la fundación del Estado federal, se produce una evolución política que implica una centralización progresiva, por comparación con las antiguas instituciones confederadas, así como una profunda democratización, que, de hecho, va a determinar la identidad politica helvética hasta el día de hoy, todo ello bajo el manto legitimador de la recuperación del pasado mítico ${ }^{57}$.

\section{EL 'RÜTLISCHWUR' COMO QUINTAESENCIA DE LA IDENTIDAD CONSTITUCIONAL SUIZA}

Los orígenes de la Confederación Helvética se fijan el marco del conflicto que enfrenta a los territorios rurales (Waldstätten) del sector sudoriental del que hoy se conoce como el lago de los Cuatro Cantones - esto es, Uri, Unterwalden y Schwyz, que acabará dando nombre la

op. cit., p. 268), Max Huber (vid. op. cit., pp. 449 y 450) o Dietrich Schlinder (vid. op. cit., pp. 478 y 479). Por el contrario, Giacometti defiende que la alte Schweizer Freiheit previa a 1798 no es idéntica a la libertad individual que introduce la Constitución en la Suiza moderna (vid. op. cit., p. 423). Según este último autor, cuya interpretación probablemente se ajusta más a la veracidad histórica pero que, por el contrario, no parece tener en cuenta la capacidad legitimadora del mito de la continuidad, en la libertad entendida como se hacía en la Edad Media no era comparable con la libertad de la Modernidad (vid. op. cit., p. 424).

55 Vid., para todo esto, Leonhard Neidhart, "Aufbau und Wandel des eidgenössischen Regierungssystems”, Schweizer Monatshefte, núm. 6, 1974, p. 419. E1 mismo autor parece mantener esta tesis más tarde, cuando se refiere al alto grado de continuidad en el desarrollo sociopolitico de la sociedad suiza. Vid. Leonhard Neidhart, "Notizen über die öffentliche Meinung im Kleinstaat", en VVAA, Staatsorganisation und Staatsfunktionen im Wandel. Festschrift für Kurt Eichenberger zum 60. Geburtstag, Helbing \& Lichtenhahn. Basilea, Frankfurt am Main, 1982, p. 444.

56 Vid. Manuel García-Pelayo, Derecho constitucional comparado, op. cit., p. 42.

57 Vid. William E. Rappard, "Considérations historiques sur la Constitution fédérale de 1848 " op. cit., p. 230. 
Confederación ${ }^{58}$ - con los Habsburgo, que pretenden imponerse como señores feudales en un área clave por el dominio que ejercía sobre el paso del Gotardo, una de las principales vías de conexión entre el próspero norte de Italia y las ricas ciudades de Borgoña y Flandes. En este contexto, los tres Orte reivindican la inmediatez imperial, esto es la consideración territorio libre dentro del Imperio, sometido únicamente al Emperador, sin la mediación de un señor. Con ello se reivindicaba, por lo tanto, un estatuto equivalente a las ciudades imperiales, circunstancia del todo excepcional en el caso de comunidades rurales como las que nos ocupan.

Los tres cantones originarios se federan a través de una serie de documentos entre los que destaca el Bundesbrief de 1 agosto de $1291^{59}$. La historiografia posterior ha dramatizado su firma a través un pretendido juramento entre los representantes de los Urkantone en el llano de Rütli el primero de agosto, el Rütlischwur, que sería el momento fundacional de la Confederación y que hoy se celebra como la fiesta nacional ${ }^{60}$. Se articula, a partir de aquí, una alianza defensiva, que se irá desarrollando a través de una compleja red de pactos que incluirá otras pequeñas entidades políticas vecinas, configurando progresivamente el territorio que, actualmente, ocupa la Confederación. En el siglo siguiente, se constituye la Tagung (la dieta federal), un órgano común permanente, y se refuerzan los poderes confederales a través del Sempacherbrief (1393), lo que va sedimentando la idea de un espacio político común, al mismo tiempo que se incorporan nuevos miembros que tienen una organización política distinta de los cantones democráticos originarios.

En este contexto, debe entenderse el relato que se ofrecerá en el contexto de la justificación del Estado Federal en 1848 en el sentido que la Confederación habría ido perdiendo sus valores democráticos

58 Actualmente, el cantón de Unterwalden se encuentra divido en dos partes, los medios cantones de Nidwalden y Obwalden. Los medios cantones son miembros de pleno derecho del Estado federal a todos los efectos, excepto por el hecho de que, contrariamente al resto de cantones su voto vale la mitad en la toma de decisiones a nivel federal -en particular, tienen un solo representante en el Consejo de los Estados, la segunda cámara de la Asamblea Federal, mientras que los demás cantones tienen dos-. Vid., en relación con ello, los arts. 142.4 y 150.2 de la Constitución federal.

59 El texto original en latín se encuentra disponible en <file:/ / / C:/Users /Usuari/AppData/Local/Temp/Lateinisches\%20Original.pdf>.

60 Efectivamente, la continuidad entre el pacto federal originario y el actual Estado federal ha sido un tópico en el relato nacional suizo, que ha sido crucial en la legitimación de unas instituciones modernas que, además, surgen de una guerra civil, la Guerra del Sonderbund. Sirva como ejemplo lo que señala el que fue rector de la Universidad de Ginebra William E. Rappard en "Le cas de la Suisse" [1950], recogido en Varia Politica op. cit., p. 238, donde afirma: "Il est incontestable aussi que malgré le grand contraste entre la Suisse primitive et la Suisse contemporaine il existe de l'une à l'autre une réelle continuité". Se trata de una posición relevante por el hecho de ser presentada por un francófono liberal, en principio, por lo tanto, desvinculado de la cultura católica, conservadora y germanófona de los Urkantone, a los que, sin embargo, percibe como núcleo fundacional del Estado federal contemporáneo. 
originales con la influencia de los cantones aristocráticos o burgueses durante la Modernidad temprana, particularmente a partir del Stanser Verkommis (1481). Precisamente, este documento será considerado por Troxler como expresión del predominio de las oligarquías urbanas y, en consecuencia, una ruptura con los Volksbünde originarios, que, por supuesto, el Estado federal pretendería restaurar ${ }^{61}$. Sin embargo, la evolución política posterior pondrá hasta cierto punto un límite al poder de las oligarquías y consolidará el papel de la Confederación como instrumento orientado a la preservación de los cantones ante eventuales amenazas externas.

Efectivamente, aunque, por supuesto, no se va a retornar al predominio de las democracias rurales de los Waldstätte, el resultado adverso de la batalla de Marignano, que supone la derrota de las tropas de la Confederación ante el Rey Francisco I de Francia determina el fin de la expansión territorial suiza, su desvinculación de las luchas de poder continentales y, en definitiva, la neutralidad, a partir de la Paz Perpetua con Francia, consecuencia inmediata de la batalla ${ }^{62}$. La neutralidad se consolida como un elemento fundamental en la Staatsidee suiza, que se vincula a su concepción como asociación defensiva, asociada, de entrada, al federalismo y, posteriormente, como se ha visto a lo largo del siglo XX, a la democracia ${ }^{63}$.

En cualquier caso, si bien es cierto que la democracia, ni que sea como institución mítica basada en las Landsgemeinden de los Waldstätten, remitirá a lo largo de la Era Moderna, las diferencias que justifican la organización federal tenderán a aumentar. En primer lugar, cabe mencionar el factor religioso, en la medida en que la Reforma va a implantarse en algunos estados confederados, mientras otros van a permanecer fieles a Roma. El peligro de división derivado del conflicto religioso va a ser finalmente sorteado $\mathrm{y}$, finalmente, con la $\mathrm{Paz}$ de Westfalia, la Confederación es reconocida como ente político diferenciado del Imperio64.

En conclusión, la historia confederada previa a la implantación de la República Helvética permite construir un relato idílico de una

61 Vid. Felix Renner, Der Verfassungsbegriff im staatsrechtichen Denken der Schweiz im 19. und 20. Jahrhundert, op. cit., p. 188.

62 William E. Rappard en "Le cas de la Suisse" op. cit., p. 241, defiende que "[s]ans neutralité, il n'y aurait certainement plus eu de Suisse après la guerre de Trente Ans".

63 Como apuntan Alois Riklin y Silvano Möckli, en "Werden und Wandel der schweizerischen Staatsidee", op. cit., p. 22, "Die schweizerische Neutralität wurde folgerichtig nicht als Ziel, sondern als Mittel zum Zweck der Unabhängigkeitbehauptung verstanden".

${ }^{64}$ Para una perspectiva de la cuestión religiosa en Suiza desde la Reforma hasta la Constitución federal de 1848, en relación con sus efectos en los equilibrios politicos dentro de la Confederación, vid. Fritz Fleiner, "Die Entwicklung der Parität in der Schweiz" [1901], en Ausgewählte Schriften und Reden, Polygraphischer. Zúrich, 1941, pp. 81-100, trabajo un poco posterior a la época que así se analiza y permite familiarizarse con la percepción de la cuestión religiosa en el momento en que se expanden las instituciones de democracia directa a nivel federal. 
confederación defensiva que protege a los pequeños estados democráticos que la configuran de la agresión de las potencias exteriores. Este relato conecta, en última instancia, con la construcción mítica del Rütlischwur y adquiere una extraordinaria fuerza de convicción en manos de los partidarios del Estado federal ante la resistencia de los cantones más conservadores, derrotados en la Guerra del Sonderbund. El relato en cuestión va a adquirir una dinámica propia a partir de la implantación del Estado federal impulsando la adopción de instituciones de democracia directa que no estaban inicialmente previstas, promoviendo así una transformación del sistema político federal, que lo singulariza en el entorno europeo, al mismo tiempo que determina tanto la autoimagen de la comunidad politica como el valor y el papel de la Constitución formal.

\section{LA IMPLANTACIÓN DE LA DEMOCRACIA DIRECTA A NIVEL FEDERAL Y SU INCIDENCIA EN LA IDEA DE CONSTITUCIÓN}

Las ideas políticas hegemónicas, que conectan la implantación del Estado federal con los orígenes del alte Eidgenossenschaft, van a ser determinantes en la evolución del sistema político en las décadas siguientes a 1848. De hecho, como ha señalado Alfred Kölz, existen un vínculo entre los procesos políticos de la Regeneración, en los que se subrayó la vinculación de las nuevas instituciones con el pasado como hemos visto, para ocultar la influencia extranjera, particularmente, la francesa- y el movimiento democrático posterior que acabó imponiendo unas robustas instituciones de democracia directa, aunque, de hecho, en 1848, la mayor parte de los cantones eran democracias representativas ${ }^{65}$. En definitiva, el mito político de la democracia originaria, vinculado a la figura romántica de Wilhelm Tell, se va imponiendo entre los radicales, que impulsarán los cambios constitucionales que convertirán a Suiza en un caso único de democracia directa en el contexto europeo, a partir de una modificación progresiva de la estructura constitucional de $1848^{66}$.

Esta transición desde la democracia representativa hegemónica al predominio de la democracia directa servirá para reforzar el vínculo con el pasado medieval, de modo que el acto fundacional de 1848 se disimulará en una historia secular, y para relativizar, asimismo, los contenidos de la Constitución, que se verán afectados de manera habitual por el funcionamiento de las instituciones de democracia directa y, particularmente, por la iniciativa popular de reforma constitucional. De esta manera, contrariamente a lo que sucede en el caso norteamericano o en el caso francés, se obvia la importancia de lo nuevo, se escapa de la mitificación de la revolución y, al estilo inglés, se

65 Vid. Alfred Kölz, Histoire constitutionnelle de la Suisse moderne. Ses fondements idéologiques et son évolution institutionnelle dans le contexte européen, de la fin de l'Ancien Régime à 1848, op. cit., p. 682.

66 Sobre el contenido original de la Constitución de 1848, vid. Rappard, Die Bundesverfassung, op. it., p. 31ss. 
trata la modernización como una expresión de las esencias ancestrales de la comunidad política.

La apelación a la democracia originaria, propia de los cantones rurales que suscribieron el Rütlischwur, va a reforzarse en los primeros años de vigencia del Estado federal hasta convertir la demanda de instrumentos de democracia directa en el plano federal en una cuestión de primer orden en el debate politico. Tras el fracaso de la revisión total de 1872, los partidarios de la profundización democrática van a lograr imponer la primera institución de democracia directa en el texto constitucional como condición de su apoyo al texto, el referéndum facultativo para las leyes aprobadas por la Asamblea Federal67.

La institución del referéndum facultativo en relación con las leyes se encontraba ya en el proyecto de Constitución jacobina de 1793, aunque no se consolidó en el Derecho constitucional francés. Sin embargo, como el ejecutivo colegial, hizo fortuna en Suiza a partir de su incorporación en la Constitución del Cantón de Sankt-Gallen en 1831, de donde se extendió a otros cantones y saltó al Derecho federal68. En todo caso, la incorporación del referéndum facultativo sobre las leyes federales acabó garantizando el éxito del proceso de revisión total en 1874, dando lugar a un texto donde la profundización democrática en relación con la Constitución de 1848 ya era evidente ${ }^{69}$.

Con el nuevo texto constitucional, se refuerzan las ideas fundamentales sobre las que se sostiene el Estado federal, a saber, el propio federalismo y la democracia, particularmente, la democracia directa que va a recibir un impulso determinante, dominando el discurso constitucional a partir de entonces y generando ulteriores modificaciones institucionales ${ }^{70}$. Así, después de las importantes

67 Vid. Yanina Welp, Nina Massüger, De Suiza a América Latina: desafíos de la democracia directa, Instituto de Ciencias de Gobierno y Desarrollo Estratégico (ICGDE). Puebla, 2013, p. 12. Sobre el proceso de revisión total que finalizó sin éxito en 1872 y la tramitación posterior de la revisión total que da lugar al nuevo texto de 1874, vid. Rainer J. Schweizer, "Die Totalrevisionen der Bundesverfassung von 1872 und 1874: Erfahrungen im blick auf die laufende Verfassungsrevision", en Piermarco Zen-Ruffinen, Andreas Auer (eds.), De la Constitution. Études en l'honneur de JeanFrançois Aubert, Helbing \& Lichtenhahn. Basilea, Frankfurt am Main, 1996, p. 105ss. De hecho, parece que el propio término referéndum, al menos, en el uso que se hace en el Derecho constitucional parece provenir de la práctica suiza. Así, en la Antigua Confederación, los delegados en la Tagung votaban ad referendum, esto es, a reserva de que lo votado fuera reenviado a y ratificado por las autoridades cantonales. Más tarde, los demócratas lo utilizaron en un sentido análogo, esto es, cuando la decisión politica es condicionada a la ratificación popular. Vid. Bernard Chantebout, Droit constitutionnel et science politique, op. cit., pp. 223-224.

68 Vid. Bernard Chantebout, Droit constitutionnel et science politique, op. cit., pp. 224.

69 En relación con la revisión total de 1874, vid. Jean-François Aubert, Traité de droit constitutionnel suisse, op. cit., p. 44ss.; y Rappard, Die Bundesverfassung, op. it., p. 315ss.

70 Vid. Kurt Eichenberger, "Hundert Jahre Schweizerische Bundesverfassung", Zeitschrift de bernischen Juristenvereins, 1974, p. 344. 
modificaciones que promueven la profundización de la democracia directa a nivel federal, finalmente, en 1891, a través de una revisión parcial de la Constitución federal, se introduce la iniciativa popular de reforma constitucional ${ }^{71}$. Con ello, se cierra el proceso de profundización democrática iniciado en 1874 y se consolida la centralidad de la democracia directa en el sistema, a partir de la reivindicación de la alte schweizerische Freiheit que ha sostenido ideológicamente el despliegue del Estado federal ${ }^{72}$.

Sin embargo, como señala Eichenberg, la profundización democrática que se opera en los tres lustros comprendidos entre $1874 \mathrm{y}$ 1891 no va en detrimento del carácter federal del sistema, que responde asimismo a la idea originaria contenida en el Rütlischwur, que, en definitiva, consiste en la asociación de tres pequeños territorios rurales organizados de modo democrático para su protección ante la amenaza feudal $^{73}$. Por ello, en palabras del clásico del Derecho público suizo Fritz Fleiner, que escribe un cuarto de siglo después de la introducción de la iniciativa popular de reforma de la Constitución, la democracia directa viene corregida por el principio federal, que permite la protección las minorias - la católica y la latina en particular - y, por lo tanto, a la preservación de la identidad politica propia de los diferentes cantones ${ }^{74}$.

71 Vid. Léon Duguit, Manuel de droit constitutionnel, E. de Boccard Éditeur. París, 1923, 4ª . edición, p. 151; así como Yanina Welp, Nina Massüger, De Suiza a América Latina: desafios de la democracia directa, op cit., p. 12; y también Bernard Degen, "Initiative populaire", Dictionnaire historique de la Suisse, 2016, disponible en <http:/ /www.hls-dhs-dss.ch/textes/f/F10386.php>.

72 En cualquier caso, debe subrayarse que, más allá de las instituciones de democracia directa federales (la iniciativa popular de reforma constitucional, los referéndums preceptivos y los referéndums facultativos), existe una diversidad de ellas en los cantones. Aparte de las mencionadas Landsgemeinde, deben mencionarse los referéndums financieros - por ejemplo, el art. 62.1.c de la Constitución del Cantón de Berna, de 6 de junio de 1993, disponible en <https://www.admin.ch/opc/de/classified-compilation/19930146/index.html\#a5>, o el art. 33.1.d de la Constitución del Cantón de Zúrich, de 27 de febrero de 2005, disponible en <https://www.admin.ch/opc/de/classifiedcompilation/20051651/index.html>; por citar dos ejemplos significativos-, y la Abberufung o revoca, esto es, la destitución popular de autoridades - que figura en el art. 28 de la Constitución del Cantón de Solothurn, de 8 de junio de 1986, disponible en <https://www.admin.ch/opc/de/classified-compilation/19860122/index.html>, o en el art. 44 de la Constitución de la República y Cantón del Ticino, de 14 de diciembre de 1997-, aunque es una institución en desuso, como señalan Ulrich Häfelin y Walter Haller, en Schweizerisches Bundesstaatsrecht, Schultess. Zúrich, 2001 (5 ${ }^{\text {a }}$ edición), p. 392. De hecho, fue suprimida en la Constitución del Cantón de Uri, de 28 de octubre de 1984, mediante referéndum el 21 de mayo de 2017. En relación con esta última institución, vid. también Bernard Chantebout, Droit constitutionnel et science politique, op. cit., p. 222. 344.

73 Vid. Eichenberger, "Hundert Jahre Schweizerische Bundesverfassung”, op. cit., p.

74 Vid. Fritz Fleiner, "Zentralismus und Föderalismus in der Schweiz" [1917], en Ausgewählte Schriften und Reden, Polygraphischer. Zúrich, 1941, p. 203. En relación con la diversidad de los cantones debe consultarse la obra Fritz-René Allemann 26mal 
Sea como sea, la introducción de las instituciones de democracia directa a nivel federal en el período comprendido entre 1874 y 1891 va a contribuir, de entrada, a la consolidación del Estado federal, legitimando su progresivo crecimiento competencial a lo largo del tiempo, dando consistencia a la comunidad politica a través de regulaciones, en la línea de otros estados federales, pero con la inestimable contribución del apoyo democrático para sostener la ampliación de los poderes de las instituciones federales ${ }^{75}$. Por otra parte, esta consistencia se logra sin la necesidad de sacralizar el texto de la Constitución, que se convierte en un instrumento más bien pragmático sometido al cambio permanente derivado del ejercicio de las instituciones de democracia directa ${ }^{76}$.

\section{CONCLUSIÓN: LA CONSTITUCIÓN COMO ACTUALIZACIÓN DEL RELATO HISTÓRICO (Y LA ESTABILIDAD POLÍTICA)}

La tesis que se ha pretendido defender en las páginas precedentes es que la modernización política en Suiza se produce a través de un proceso de recuperación de las instituciones históricas, que permiten consolidar el federalismo y la democracia como ideas fundamentales del sistema. En este sentido, se rechaza la adhesión a un discurso universalista, al estilo de los revolucionarios franceses o norteamericanos, y se construye un estado moderno sobre los mimbres de la tradición, ni que sea transformándola y manipulándola para hacer efectiva la legitimación de las nuevas instituciones. Sin embargo, el camino escogido para la consolidación del nuevo Estado federal, en la medida que enlaza con la pretendida democracia rural de los cantones originarios, va a tener consecuencias desde el punto de vista de su propia evolución, con la incorporación a lo largo del último cuarto del siglo XIX de instituciones de democracia directa que van a definir la sustancia constitucional del sistema hasta nuestros dias, más allá de las numerosas reformas parciales y la revisión total de 1999 que ha experimentado desde entonces ${ }^{77}$.

Schweiz. Yo he manejado la versión francesa: Vingt-six fois la Suisse, L'Aire-Ex Libris. Lausana, 1985 (edición a cargo de Jean-Jacques Langendorf).

75 En relación con la progresiva ampliación de las competencias de los estados federales a medida que la vida social y económica va haciendo más compleja a lo largo del siglo XX, vid. Gérard Marcou, "L'évolution récente du fédéralisme allemand sous l'influence de l'intégration européenne et de l'unification", Revue de Droit Public, $\mathrm{n}^{\circ} .4$, 1995, p. 883.

76 En la medida en que el cuerpo electoral no sólo tiene la facultad de elegir los órganos parlamentarios representativos, sino que, además, dispone de facultades de toma de decisión por sí mismo, sin que el ejercicio de estas facultades dependa de la voluntad de ningún otro órgano del Estado, el sistema suizo sería un ejemplo acabado de democracia directa. Vid. Andreas Auer, Giorgio Malinverni, Michel Hottelier, Droit constitutionnel Suisse. I. L'Etat, op. cit., p. 190.

77 Sin embargo, quizá debido a una cierta aversión a los grandes principios y un cierto espíritu pragmático que se compadece bien con la apertura al cambio del texto de la Constitución, el principio democrático, como tal, no figura en la Carta Magna, a 
Ello ha tenido como consecuencia una notable estabilidad, basada en las convicciones comunes en relación con el relato historicista hegemónico; y, por otra parte, ha impulsado las dinámicas de concertación del sistema, de modo que se ha producido una consolidación de la diversidad en el contexto federal, así como una profundización democrática de modo paralelo. La muestra más notoria de la influencia de los cambios constitucionales introducidos en el último cuarto del siglo XIX, reivindicando la antigua democracia de los cantones rurales originarios, es el procedimiento de consulta que se abre en relación con la tramitación de cualquier ley federal, cuyos orígenes se remontan a 194778. El hecho de que esté sometida al referéndum facultativo produce un incentivo para la búsqueda del consenso antes de su aprobación, de modo que no sea discutida posteriormente, lo que, en última instancia, abre el proceso legislativo a los actores sociales y lo hace particularmente inclusivo ${ }^{79}$.

De este modo, el régimen político suizo se diferencia de los sistemas parlamentarios dominantes en el Occidente europeo, en la medida que no se espera que las elecciones den lugar a una mayoría parlamentaria que implemente un proyecto legislativo propio, sino que se promueven amplios consensos que dan una especial legitimidad y solidez a las decisiones que se toman, aunque ello, por supuesto, implica también la existencia de dinámicas conservadoras, en la medida que las exigencias de la concordancia hacen muy costosas las innovaciones políticas; siendo, por otra parte, inimaginable la alternativa, de modo que la misma coalición de gobierno se mantiene desde la década de los cincuenta ${ }^{80}$.

En definitiva, el sistema acaba combinando una gran estabilidad politica y un alto nivel de cohesión a partir del vigor de las instituciones democráticas y la gestión adecuada del pluralismo, todo lo cual se

pesar de constituir el elemento central junto con el federalismo de la identidad constitucional suiza. Vid., en este sentido, Ulrich Häfelin y Walter Haller, Schweizerisches Bundesstaatsrecht, op. cit., pp. 53-54.

78 Vid. Hanna Muralt Müller, "Vernehmlassungsverfahren - helvetisches Ritual oder modernes partizipatorisches Instrument der Konkordanzdemokratie", Gesetzgebung heute / Législation d'ajourd'hui / Legislazione oggi / Legislaziun dad oz (LeGes), $\mathrm{n}^{\circ} .2$, 1997 , p. 19. Sobre el procedimiento de consulta, vid., asimismo, Yannis Papadopoulos, "La consultation: un outil de gouvernabilité? - Fonctions et disfonctions de la phase préparlamentaire", Gesetzgebung heute / Législation d'ajourd'hui / Legislazione oggi / Legislaziun dad oz (LeGes), $n^{\circ}$. 2, 1997, pp. 41-60.

79 Vid. Riccardo L. Jagmetti, "Der Bürger im Entscheidungsprozeß", en VVAA, Staatsorganisation und Staatsfunktionen im Wandel. Festschrift für Kurt Eichenberger zum 60. Geburtstag, Helbing \& Lichtenhahn. Basilea, Frankfurt am Main, 1982, p. 365 ss.

${ }^{80}$ La coalición la forma cuatro fuerzas políticas que se reparten el Consejo Federal, el ejecutivo directorial, a saber: la Democracia Cristiana (un consejero), el Partido Socialdemócrata (dos consejeros), la Unión Democrática de Centro (dos consejeros), y el Partido Liberal Radical (dos consejeros). Vid., sobre la llamada fórmula mágica, Maurice Croisat, Le fédéralisme dans les démocraties contemporaines, Monchrestien. París, 1999 ( $3^{a}$ edición), p. 78. 
fundamenta, en última instancia, en el éxito del relato histórico a la hora de consolidar una identidad constitucional asumida por la mayoria de la población e incorporar los principios e instituciones del constitucionalismo moderno sin apelar a una ruptura con el pasado, sino más bien a su recuperación en su forma más prístina y auténtica, esto es, la pretendida democracia originaria de los Waldstätten que suscribieron el Rütlischwur.

\section{BIBLIOGRAFÍA}

Allemann, Fritz-René, Vingt-six fois la Suisse, L'Aire-Ex Libris. Lausana, 1985 (edición francesa a cargo de Jean-Jacques Langendorf).

Aubert, Jean-François, Traité de droit constitutionnel suisse, Ides et Calendes. Neuchâtel, 1967.

Auer, Andreas; Giorgio Malinverni, Michel Hottelier, Droit constitutionnel Suisse. I. L'Etat, Stämpfli. Berna, 2000.

Bridel, Marcel, Précis de droit constitutionnel et public suisse I, Payot. Lausana, 1965.

Chantebout, Bernard, Droit constitutionnel et science politique, Economica. París, 1978.

Croisat, Maurice, Le fédéralisme dans les démocraties contemporaines, Monchrestien. Paris, 1999 (3ª edición).

Degen, Bernard, "Initiative populaire", Dictionnaire historique de la Suisse, 2016, disponible en <http://www.hls-dhsdss.ch/textes/f/F10386.php>.

Domeisen, Norbert, Schweizer Verfassungsgeschichte, Geschichtphilosophie und Ideologie, Lang. Berna, 1978.

Duguit, Léon, Manuel de droit constitutionnel, E. de Boccard Éditeur. París, 1923 (4 ${ }^{\mathrm{a}}$. edición).

Dunn, Thomas, Die richtige Verfassung, Schulthess. Zúrich, 1971.

Eichenberger, Kurt, "Hundert Jahre Schweizerische Bundesverfassung", Zeitschrift de bernischen Juristenvereins, 1974, pp. 337-345.

Fleiner, Fritz, "Die Gründung des Schweizerischen Bundesstaates im Jahre 1848" [1898], en Ausgewählte Schriften und Reden, Polygraphischer. Zurich, 1941, pp. 53-80

- "Die Entwicklung der Parität in der Schweiz" [1901], en Ausgewählte Schriften und Reden, Polygraphischer. Zúrich, 1941, pp. 81-100.

- "Zentralismus und Föderalismus in der Schweiz" [1917], en Ausgewählte Schriften und Reden, Polygraphischer. Zúrich, 1941, pp. 197-203. 
Fleiner, Thomas, "Die Stellung der Minderheiten im schweizerischen Staatsrecht", a Ulrich Häfelin, Walter Haller i Dietrich Schlindler (editors), Menschenrechte, Föderalismus, Demokratie. Festschrift zum 70. Geburtstag von Werner Hägi, Schulthess. Zúrich, 1979, pp. 115-128.

- "El federalismo suizo: la influencia del federalismo americano", en VVAA, El federalismo en Europa, Hacer. Barcelona, 1993, pp. 9-43 (versión castellana, a partir del original francés, a cargo de Josep Maria Solé Alseda). "El federalismo suizo: la influencia del federalismo americano", en VVAA, El federalismo en Europa, Hacer. Barcelona, 1993, pp. 9-43 (versión castellana, a partir del original francés, a cargo de Josep Maria Solé Alseda).

Garcia-Pelayo, Manuel, Derecho constitucional comparado, Alianza, Madrid, 1984.

Häberle, Peter, Europäische Verfassungslehre, Nomos. BadenBaden, 2011 (6 ${ }^{\mathrm{a}}$. edición).

Häfelin, Ulrich, Walter Haller, Schweizerisches Bundesstaatsrecht, Schultess. Zúrich, 2001 (5 ${ }^{\mathrm{a}}$. edición).

His, Eduard, Geschichte des neuen Schweizerischen Staatsrechts I. Die Zeit der Helvetik und der Vermittlungsakte. 1798 bis 1813, Helbing \& Lichtenhahn. Basilea, 1920.

- Geschichte des neuen Schweizerischen Staatsrechts III. Der Bundesstaat von 1848 bis 1914, Helbing \& Lichtenhahn. Basilea, 1938

Hutson, James H., The Sister Republics. Switzerland and the United States from 1776 to the Present, Library of the Congress. Washington, 1991.

Jagmetti, Riccardo L., "Der Bürger im Entscheidungsprozeß", en VVAA, Staatsorganisation und Staatsfunktionen im Wandel. Festschrift für Kurt Eichenberger zum 60. Geburtstag, Helbing \& Lichtenhahn. Basilea, Frankfurt am Main, 1982, p. 363-373.

Jaria i Manzano, Jordi, "El federalismo suizo. Una respuesta a una sociedad plural", Revista Vasca de Administración Pública / HerriArduralaritzako Euskal Aldizkaria, nº. 61(I), 2001, pp. 89-136.

Kölz, Alfred, Histoire constitutionnelle de la Suisse moderne. Ses fondements idéologiques et son évolution institutionnelle dans le context européen, de la fin de l'Ancien Régime à 1848, Stämpfli, Bruylant. Berna, Bruselas, 2006.

Llanque, Marcus, Politische Ideengeschichte - Ein Gewebe politischer Diskurse, Oldenbourg. Múnich, 2008.

Marcou, Gérard, “L'évolution récente du fédéralisme allemand sous l'influence de l'intégration européenne et de l'unification", Revue de Droit Public, nº. 4, 1995, pp. 883-919.

Muralt Müller, Hanna, "Vernehmlassungsverfahren - helvetisches Ritual oder modernes partizipatorisches Instrument der 
Konkordanzdemokratie", Gesetzgebung heute / Législation d'ajourd'hui / Legislazione oggi / Legislaziun dad oz (LeGes), nº. 2, 1997, pp. 17-39.

Neidhart, Leonhard, "Aufbau und Wandel des eidgenössischen Regierungssystems”, Schweizer Monatshefte, núm. 6, 1974, pp. 419429.

— "Notizen über die öffentliche Meinung im Kleinstaat", en VVAA, Staatsorganisation und Staatsfunktionen im Wandel. Festschrift für Kurt Eichenberger zum 60. Geburtstag, Helbing \& Lichtenhahn. Basilea, Frankfurt am Main, 1982, pp. 443-460.

Papadopoulos, Yannis, "La consultation: un outil de gouvernabilité?

Fonctions et disfonctions de la phase préparlamentaire", Gesetzgebung heute / Législation d'ajourd'hui / Legislazione oggi / Legislaziun dad oz (LeGes), nº. 2, 1997, pp. 41-60.

Rappard, William E., Die Bundesverfassung, Polygraphischer. Zúrich, 1948 (versión alemana, a partir del original francés, a cargo de A. Lätt).

- "Considérations historiques sur la Constitution fédérale de 1848” [1948], en Varia Politica, Poligraphiques. Zúrich, 1953, pp. 217235.

— "Le cas de la Suisse" [1950], Varia Politica, Poligraphiques. Zúrich, 1953, pp. 236-246.

Renner, Felix, Der Verfassungsbegriff im staatsrechtichen Denken der Schweiz im 19. und 20. Jahrhundert, Schultess. Zúrich, 1968.

Riklin, Alois; Silvano Möckli, "Werden und Wandel der schweizerischen Staatsidee", en Alois Riklin (ed.), Handbuch Politisches System der Schweiz. 1. Grundlagen / Manuel Système politique de la Suisse. 1. Le contexte, Paul Haupt. Berna, Stuttgart, 1983, pp. 9-118.

Ruffieux, Roland, "Les données de l'histoire constitutionnelle", Alois Riklin (ed.), Handbuch Politisches System der Schweiz. 1. Grundlagen / Manuel Système politique de la Suisse. 1. Le contexte, Paul Haupt. Berna, Stuttgart, 1983, pp. 119-211.

Sánchez Ferriz, Remedio, "El sistema político suizo", en Juan Ferrando Badía (ed.), Regimenes politicos actuales, Tecnos. Madrid, 1995 (3ª edición), pp. 497-534.

Schweizer, Rainer J., "Die Totalrevisionen der Bundesverfassung von 1872 und 1874: Erfahrungen im blick auf die laufende Verfassungsrevision", en Piermarco Zen-Ruffinen, Andreas Auer (eds.), De la Constitution. Études en l'honneur de Jean-François Aubert, Helbing \& Lichtenhahn. Basilea, Frankfurt am Main, 1996, p. 101-114.

Spitteler, Carl, Imago. Narraciones breves. Gustav, Rueda. Madrid, 2002 (versión castellana no acreditada).

Von Schiller, Friedrich, Guillermo Tell, Planeta, Barcelona, 1982 (edición castellana de Justo Molina, con introducción de Alfonsina Janés Nadal). 
Welp, Yanina; Nina Massüger, De Suiza a América Latina: desafíos de la democracia directa, Instituto de Ciencias de Gobierno y Desarrollo Estratégico (ICGDE). Puebla, 2013.

Wyduckel, Dieter, "La soberanía en la historia de la dogmática alemana", Fundamentos. Cuadernos monográficos de Teoría del Estado, Derecho Público e Historia Constitucional 1, 1998, disponible en <http:/ / 156.35.33.98/constitucional/fundamentos/primero/pdf/wydu cke.pdf>.

Fecha de envio / Submission date: 18/01/2021

Fecha de aceptación / Acceptance date: 11/03/2021 